\title{
QUEEN'S
UNIVERSITY
BELFAST
}

\section{Managing Type 2 diabetes as a couple: The influence of partners' beliefs on diabetes distress over time}

Berry, E., Davies, M., \& Dempster, M. (2018). Managing Type 2 diabetes as a couple: The influence of partners' beliefs on diabetes distress over time. Diabetes Research and Clinical Practice, 141, 244-255.

https://doi.org/10.1016/j.diabres.2018.05.020

\section{Published in:}

Diabetes Research and Clinical Practice

\section{Document Version:}

Peer reviewed version

Queen's University Belfast - Research Portal:

Link to publication record in Queen's University Belfast Research Portal

\section{Publisher rights}

(c) 2018 Elsevier B.V. All rights reserved.

This manuscript version is made available under the CC-BY-NC-ND 4.0 license http://creativecommons.org/licenses/by-nc-nd/4.0/,which permits distribution and reproduction for noncommercial purposes, provided the author and source are cited

\section{General rights}

Copyright for the publications made accessible via the Queen's University Belfast Research Portal is retained by the author(s) and / or other copyright owners and it is a condition of accessing these publications that users recognise and abide by the legal requirements associated with these rights.

Take down policy

The Research Portal is Queen's institutional repository that provides access to Queen's research output. Every effort has been made to ensure that content in the Research Portal does not infringe any person's rights, or applicable UK laws. If you discover content in the Research Portal that you believe breaches copyright or violates any law, please contact openaccess@qub.ac.uk. 
Title: Managing Type 2 diabetes as a couple: the influence of partners' beliefs on diabetes distress over time.

\section{Authors names and affiliations:}

Berry, Emma1; Queen's University Belfast, School of Psychology, Northern Ireland; eberry05@qub.ac.uk

Davies, Mark²; Belfast City Hospital, Clinical Psychology Department, Northern Ireland; mark.davies@belfasttrust.hscni.net

Dempster, Martin¹; Queen's University Belfast, School of Psychology, Northern Ireland; m.dempster@qub.ac.uk

Main affiliation: Queen's University Belfast, School of Psychology, Northern Ireland

Corresponding Author: Miss Emma Berry; eberry05@qub.ac.uk; (+44)7921094169

Present/permanent address: Queen's University Belfast, School of Psychology, David Keir Building, 18-30 Malone Road, Belfast, Northern Ireland, BT9 5BN

Declarations of interest: none. 


\section{Highlights:}

- Diabetes beliefs held by couples living with Type 2 diabetes influence emotional wellbeing.

- Partners' beliefs have an indirect impact on diabetes distress in their loved ones with diabetes.

- The direct and indirect effects of diabetes beliefs on emotional distress endure overtime. 


\begin{abstract}
Aims: Partners and spouses have an important role in supporting healthy self-care in adults with Type 2 diabetes. While evidence has shown that the beliefs held by people with diabetes influence emotional wellbeing, little is known about the long-term impact of partners' illness beliefs on diabetes distress.
\end{abstract}

Methods: Persons with Type 2 diabetes (pwt2d) and their partners completed a questionnaire at baseline ( $\mathrm{N}=75$ couples) and 12 months later $(\mathrm{N}=45$ couples). Measures included demographic/ clinical parameters, the Revised Illness Perception questionnaire, and the Diabetes Distress Scale. A repeated measures ANOVA used to examine change in measures over time. Multiple regression and moderation analysis were used to explore the indirect influence of partners beliefs on diabetes distress at baseline and follow-up.

Results: Illness perceptions and diabetes distress in pwt2d and partners did not change overtime. Partners' beliefs about the controllability, chronicity, and predictability of symptoms of diabetes moderated the relationship between the corresponding pwt $2 \mathrm{~d}$ beliefs and diabetes distress. These indirect effects were observed across both time points.

Conclusions: Conflicting illness perceptions about the controllability and chronicity of diabetes, and congruous negative perceptions about diabetes symptoms among couples sustain distress overtime. Targeting the beliefs of couples to improve communication and understanding may reduce diabetes distress.

Key words: Type 2 Diabetes Mellitus; Psychological Adjustment; Social Support; Interpersonal Relations. 


\section{Introduction}

Receiving a diagnosis of Type 2 diabetes can impact entire families as well as the person involved. With Type 2 diabetes being an almost entirely self-managed condition, it is inevitable that partners will influence diabetes self-management. Relationship quality, specifically the degree to which couples living with Type 2 diabetes disagree on matters $[1,2]$ or have conflicting views about Type 2 diabetes [3], can influence emotional wellbeing and diabetes self-care. Psychosocial adaptation among couples living with Type 2 diabetes is hugely important in shaping health-related outcomes; and a key ingredient of this is good communication.

Understanding the nature of communication between couples, and how specific dialogues can lead to greater distress, is a complex process. One way that we can attempt to understand the conversations that take place is through the beliefs couples hold about the condition. How partners identify with or attach meaning to their loved one's condition has been shown to influence adjustment. Wu and colleagues found that when spouses of people with prostate cancer perceived their loved one to have greater control over their condition, this also incited the belief that their loved one's illness would be impermanent [4]. This, in effect, predicted better quality of life in patients 6 months later [4]. Similarly, Dempster et al. found that Oesophageal cancer survivors' stronger perceptions about the consequences of their condition on day to day life was associated with increased anxiety, and that this association is especially potent when their partners also perceived the cancer to have serious consequences on daily life [5]. A poor understanding of their condition was associated with higher levels of depression. Interestingly they found that this association was strongest when partners held an opposing belief, that their loved one had a good understanding of their condition [5].

Likewise, incongruous beliefs between people with Type 2 diabetes and their partners can negatively impact diabetes self-management [6]. Specifically, when couples hold conflicting perceptions about personal control and understanding of Type 2 diabetes, self-care behaviour diminishes [6]. Other work demonstrates how partners' beliefs about the controllability and consequences of Type 2 diabetes mediates the positive relationship between the corresponding patient beliefs and monitoring of blood glucose [7]. Furthermore, Dimitraki and Karademas found that the association between higher consequence beliefs among partners and partner anxiety is more pronounced when their loved ones with diabetes perceive their own condition to have less of an impact on day to day life [8]. 
Aside from the evidence described, little is known about the influence of partners' illness perceptions on diabetes distress overtime. Diabetes distress is associated with long term blood glucose and therefore is clinically meaningful [9-11]. Exploring interactions between people with diabetes' and partners' beliefs would provide a greater understanding of the mechanisms underpinning poor communication, and which sustain distress. Indeed, previous evidence has shown that illness perceptions among people with Type 2 diabetes do not change over time [12]. This suggests the impact that illness beliefs have on diabetes distress (whether positive or negative) is a lasting one in the absence of an appropriate intervention. On the basis of this previous work it is predicted that there will be little to no change in illness perceptions among couples in the absence of an appropriate psychosocial or familybased intervention. This would provide necessary evidence in support of the need to intervene.

Research Aims:

1. To examine whether illness perceptions in people with Type 2 diabetes and their partners are useful predictors of diabetes distress.

2. To explore the indirect effect of partners' illness perceptions on diabetes distress

3. To compare illness perceptions and diabetes distress in people with Type 2 diabetes and their partners at baseline and 12 months later.

4. To examine whether partners' illness perceptions have an enduring impact on diabetes distress in people with Type 2 diabetes - are similar interaction patterns observed 12 months later?

\section{Methods}

\subsection{Subjects}

Persons with Type 2 diabetes (pwt2d) and their partners (defined as a spouse, romantic partner, family member, or close friend who lives with the pwt2d) were recruited using the databases of five General Practices in Northern Ireland. A total of 950 adults with a diagnosis of Type 2 Diabetes were posted out an information sheet, a consent form, a battery of questionnaires for themselves (pwt2d) and a battery of questionnaires for their partner (if appropriate) to complete and return in a freepost envelope. Twelve months later, all couples who completed and returned the first questionnaires were posted a follow-up study pack. 


\subsection{Materials}

The pwt2d and partner questionnaire scales comprised the following outcome measures (original measures were adapted for partners):

- Demographics and Clinical Parameters: Gender, age, ethnicity, relationship status, children living at home, relationship with person completing the partner questionnaire, duration since diagnosis, diabetes-related complications, diabetes treatment taken (pwt2d questionnaire). Gender, age, ethnicity, partner has/ has not got diabetes, and diagnosis of other type of chronic physical illness (partner questionnaire).

- Diabetes Distress Scale (DDS) [13]: 17-item validated questionnaire assessing emotional distress across four sub-domains_-partners were administered a partner adjusted version of the validated scale due to the lack of availability of a comparable scale at the time of baseline data collection (more information below). Sub-domains are as follows: 'physician-related distress', 'emotional burden', 'interpersonal distress', and 'regimenrelated distress'. Each DDS scale item was reworded for partners, for example "Feeling that I am not sticking closely enough to a good meal plan" was reworded as "Feeling that my partner is not sticking closely enough to a good meal plan" and "Feeling that my doctor doesn't know enough about diabetes and diabetes care" was rephrased as "Feeling that my partner's doctor doesn't know enough about diabetes and diabetes care". Participants rate each item using a 6 point Likert scale $(1=$ no problem, $6=$ a serious problem). Mean item scores of $<2.0$ are suggestive of 'low diabetes distress', scores of $2.0 \leq 2.9$ are suggestive of 'moderate distress', and scores $\geq 3.0$ are suggestive of 'high distress' [14]. Cronbach's internal reliability alpha coefficients for each pwt2d and partner subscale ranged from 0.75 to 0.90 [15]. Moreover, all partner DDS subscales were significantly correlated with partner depression score (measured using Beck's Depression Inventory [16] — scale not featured in the main analysis) (Pearson's correlations ranged from $r=0.40$ to $r=0.62$; all $p<0.01$ ), demonstrates acceptable construct validity in light of previous work $[9,17]$.

- Revised Illness Perception Questionnaire (IPQ-R) [18]—partners were administered a partner adapted version of the validated scale in line with previous work [6]. The first section asks participants about their experience of symptoms ('illness identity') using a list of 14 general symptomology (e.g. fatigue, dizziness) (possible score of 0-14). Sections two and three consists of 7 subscales each using a 5-point Likert scale $(0=$ strongly disagree, $5=$ strongly agree or reversed; maximum scores range from 20-30): 
'timeline acute/ chronic', 'consequences', 'timeline cyclical', 'personal control', 'treatment control', 'coherence', and 'causes' (emotional, behavioural, and external causal beliefs were extracted through principle components analysis). Higher scores on the subscales denote stronger beliefs about the frequency of symptoms attributed to diabetes, the chronicity of diabetes, the consequences of diabetes, the cyclical nature of diabetes symptoms, the controllability of diabetes, understanding of diabetes, and causes attributed to the condition [18]. The emotional representations subscale was not included in the main analysis due to its similarity with DDS items. Cronbach's internal reliability alpha coefficients for each pwt $2 d$ and partner subscale ranged from 0.65 to 0.90 [15]. The adjustment of partner IPQ-R items was guided by previous work examining illness perceptions in couples living with diabetes $[6,19]$

\subsection{Data analysis}

SPSS version 20 was used to analyse results. Baseline descriptives are reported for the sample, alongside an independent samples t-test to assess significant differences between participants who responded and those who did not respond to the 12 month follow-up questionnaire. To firstly explore the indirect influence of partners' illness perceptions on diabetes distress at baseline, interaction terms were created for each mean-centred pwt $2 \mathrm{~d}$ and partner baseline IPQ-R score. Separate hierarchical regression analyses were then performed across each diabetes distress subscale at baseline. Baseline demographic and medical covariates were entered into the first block and baseline pwt $2 \mathrm{~d}$ and partner illness perceptions and interaction terms were entered into the second block. Demographic and medical covariates with more than two levels were entered as dummy codes. Backward elimination was used in order to produce the most parsimonious model for each outcome variable. All variables were standardized prior to analysis. Any significant interaction terms remaining in the final model for each outcome measure were subjected to simple slopes analysis. This assessed the conditional effect of partners illness perception score at three levels of the corresponding pwt $2 \mathrm{~d}$ illness perception score-below 1 standard deviation of the mean, at the mean, and above 1 standard deviation of the mean.

A repeated measures Analysis of Variance was performed in order to examine change in pwt2d and partners' illness perceptions and diabetes distress between baseline and follow-up. Influenced by the findings drawn from the repeated measures ANOVA, the method of 
analysis described above was repeated on the data at the second assessment point (with follow-up predictors and follow-up diabetes distress outcomes), to explore whether any of the initial observations sustained after 12 months. A comparison between time points was deemed appropriate given the absence of change in scores, thus rendering the use of change/ difference scores or the regression variable method [20] inappropriate. The regression models produced for each diabetes distress subscale achieved statistical significance, demonstrating that the sample at time 1 and time 2 had sufficient power. Further, a sample size of 45 was sufficient to detect an R-squared value of at least 0.494 (the smallest value detected at time 2) with $80 \%$ power in a regression model with 24 predictors (the total number listed in Table 2), using an alpha value of 0.05 .

\section{Results}

Seventy-five couples completed and returned questionnaires at time point one (baseline assessment) and 45 completed and returned questionnaires at time point two (12 month follow-up). Fifty questionnaires were returned at follow-up; however 5 did not include the partner questionnaire scale and therefore could not be included in the longitudinal analysis. There were no significant differences between responders and non-responders to the followup survey on demographic/ clinical parameters, and therefore baseline parameters were used to describe the sample as a whole. Moreover, clinical parameters such as onset of diabetesrelated complications and diabetes treatment taken (medication/ insulin) did not change during the 12 month period between testing, and there was no significant change in $\mathrm{HbA1c}$. However, six partners reported that they had been diagnosed with a chronic illness (not diabetes) since the baseline assessment point. This had no influence on pwt2d DDS score, however a mixed ANOVA revealed an interaction between time (within factor) and change in partner health status (between factor) within partner diabetes distress as the dependent variable $(F(1,44)=4.39, p=.042)$. The interaction plot suggested that being diagnosed with a chronic illness increases diabetes distress in partners $(1.27 \pm 2.00)$.

Pwt2d were predominately male (68\%), Caucasian (96\%), with an average age of 67.9 years. The average length of time since diagnosis was just under 10 years and most pwt $2 \mathrm{~d}$ took medication $(89.3 \%)$, while a small proportion took insulin (14.7\%). On average, pwt2d had relatively well-controlled HbA1c (7\% (53.5 mmol/mol)) (NICE guidelines state $\leq 7 \%(\leq 53$ $\mathrm{mmol} / \mathrm{mol}$ ) is within normal range for people with diabetes) [21] and low levels of diabetes distress $(\leq 2.0)[14]$ for pwt2d (1.35) and partners (1.38). The highest scores were seen for 
regimen-related distress and emotional burden among pwt $2 \mathrm{~d}$ ( 1.56 and 1.57 consecutively) and female partners (1.60 and 1.61 consecutively); however scores did not achieve the threshold for moderate distress. See Table 1 for full demographic/ clinical information and see Tables A1 and A2 in Appendix B for baseline and follow-up means and standard deviations across each pwt2d and partner IPQ-R and DDS subscale.

\subsection{Are illness perceptions among people with Type 2 diabetes and their partners' useful predictors of diabetes distress?}

The covariates accounted for $30.8 \%$ of variance in baseline regimen-related distress [adjusted $\left.R^{2}=0.308 ; F(7,68)=4.562 ; p<.001\right], 50.2 \%$ of variance in baseline emotional burden [adjusted $\left.R^{2}=0.502 ; F(9,66)=8.156 ; p<.001\right], 41.3 \%$ of variance in baseline interpersonal distress [adjusted $R^{2}=0.413 ; F(7,68)=6.549 ; p<.001$ ], and $35.3 \%$ of the variance in baseline physician-related distress [adjusted $\left.R^{2}=0.353 ; F(6,69)=7.458 ; p<.001\right]$. Key IPQ-R predictors of distress included greater perception of diabetes-related consequences, lower perceived personal control in pwt $2 \mathrm{~d}$, stronger perception of coherence in partners, and greater experience of diabetes-related symptoms in pwt $2 \mathrm{~d}$ and partners. High chronicity beliefs in partners and low chronicity beliefs in people with Type 2 diabetes also predicted greater distress.

\subsection{Indirect influences of partners' illness perceptions on diabetes distress at baseline}

Significant interactions were observed for each of the diabetes distress subscales at baseline (Table 2). With baseline regimen-related distress as the outcome variable, there is an interaction between pwt $2 \mathrm{~d}$ and partners' perceived personal control. The simple slopes analysis shown in Figure 1 suggests that perceived personal control in pwt2d is negatively associated with diabetes distress (lower personal control equates to higher distress). Moreover, when pwt2d perceive that they have less control of diabetes while partners perceive that they have more control of their own condition, diabetes distress is highest. With baseline emotional burden as the outcome variable, an interaction is observed between pwt2d and partners' timeline cyclical perceptions (frequency of diabetes-related symptoms overtime). The simple slopes analysis in Figure 2 suggests that perceived timeline (cyclical) in pwt $2 \mathrm{~d}$ is positively associated with emotional burden (emotional burden is greater among individuals who perceive that the symptoms of their condition are less predictable/ stable). 
This association is especially pronounced when partners also perceive the symptoms of their loved ones' Type 2 diabetes as less predictable/ stable.

Furthermore, with baseline interpersonal distress as the outcome variable, there is an interaction between pwt $2 \mathrm{~d}$ and partners' perceived diabetes chronicity. The simple slopes analysis in Figure 3 indicates that perceived chronicity in pwt2d is negatively associated with interpersonal distress (perceiving diabetes as a temporary condition leads to greater interpersonal distress). However, when pwt2d perceive their condition to be more transient by nature while their partners perceive their loved ones' condition to be more chronic by nature, interpersonal distress is highest. Lastly, with baseline physician-related distress as the outcome measure, an interaction is observed between pwt $2 \mathrm{~d}$ and partners' perceived chronicity and physician-related distress. Simple slopes analysis suggested a similar pattern to the graph displayed in Figure 3 and described above.

\subsection{Assessing change in diabetes beliefs and diabetes distress in people with Type 2 diabetes and their partners across time}

Repeated measures ANOVA assessed illness perception and diabetes distress scores in people with Type 2 diabetes and their partners between baseline and 12 month-follow-up. No significant time effects were found between baseline and 12 month-follow-up scores across any of the diabetes distress subscales for pwt $2 \mathrm{~d}$ and partners, with the exception of physicianrelated distress for partners. Physician-related distress significantly increased for partners between baseline and 12 month follow-up $(1.15 \pm 1.45)(F(1,44)=5.049, p=.030)$, approaching a medium effect $(d=0.44)$ [22]. There was a trend towards increased diabetes distress overtime for both pwt2d and partners; however this did not reach statistical significance. The findings indicate that illness perceptions and diabetes distress scores are stable overtime. As no change was observed between time points, change/ difference scores or the regression variable method were deemed inappropriate for longitudinal analysis, and instead the regression models at time 1 and time 2 were compared.

\subsection{Do partners' illness perceptions have an enduring impact on diabetes distress in people with Type 2 diabetes?}

Table 2 displays the multiple regression models produced for the 12 month follow-up data, along with the adjusted $R^{2}$ and $F$ ratio for each. Predictors at both baseline and follow-up included younger age in pwt $2 \mathrm{~d}$ and greater perception of the consequences of diabetes, lower perceived personal control, and greater experience of diabetes-related symptoms among 
pwt2d. Key predictors emerging at the 12 month follow-up only included lower perceived personal control in partners and the absence of children living at home.

Significant interactions between pwt $2 \mathrm{~d}$ and partners perception of personal control (for regimen-related distress), between pwt2d and partners timeline cyclical perceptions (for emotional burden), and between pwt2d and partners timeline acute/chronic perceptions (for interpersonal distress) were observed at baseline and remained at 12 months. The interactions produced similar effects to the corresponding simple slopes graphs displayed in Figures 1-3 (see Figures A1-3 in Appendix A for the corresponding simple slopes at 12 months).

\section{Discussion}

Illness perceptions held by couples living with Type 2 diabetes are important determinants of diabetes distress. When people with Type 2 diabetes and their partners have incongruous beliefs about Type 2 diabetes, this generates greater diabetes distress. Equally, when certain negative perceptions between couples are congruent, this may also exacerbate distress. This study also found no meaningful change in illness perceptions and diabetes distress across a 12 month time frame. This implies that illness perceptions which positively or negatively influence diabetes distress will continue to do so overtime unless actively targeted. Notably, this study suggests that partners' beliefs will continue to have a moderating influence on the beliefs held by people with Type 2 diabetes.

\subsection{Key factors sustaining diabetes distress over time}

The findings suggest that people with Type 2 diabetes who are younger in age have a greater propensity for diabetes distress which supports previous work [23]. Beliefs about the consequences of Type 2 diabetes was also a reliably strong predictor of diabetes distress. This suggests that when people perceive threat from their diabetes they may develop specific fears and concerns about how this threat will impose itself on day to day life. They may accurately or inaccurately predict the potential consequences or risks of Type 2 diabetes [24], and the conclusions they draw may continue to elicit significant distress unless appropriately addressed.

\subsubsection{The moderating influence of partners' diabetes beliefs}

Previous research demonstrates that when people with diabetes feel that they are not in control of or able to influence their condition, they feel more distressed $[25,26]$ However the 
current findings suggest a different pattern when partners are involved. Partners appear to enhance regimen-related distress when they believe that their loved one has more control over their diabetes than the person with diabetes believes. It is possible that individuals with diabetes feel misunderstood or pressurised if their partner overlooks or is unaware of signals of struggle. Perhaps this occurs through a lack of communication about how things are really going with their self-management, and it seems that this pattern of misunderstanding has a lasting impact on emotional wellbeing. Likewise, interpersonal distress is greater among people with diabetes who believe their condition will not last forever, but particularly when their partner believes the opposite. For people with diabetes, such beliefs may signify difficulties with accepting their diagnosis; perhaps by avoiding the (scary) truth or through a lack of understanding of the condition. Meanwhile, if partners are more forthright about the longevity of the condition, this may arouse tension in the relationship.

Congruent negative perceptions may also lead to greater distress by provoking or rousing unhelpful thoughts about diabetes. When people with Type 2 diabetes perceive that the symptoms of their condition are less predictable, the burden of living with diabetes is greater. However when partners share this belief, distress towards symptoms is enhanced.

\subsection{Practical Implications}

Targeting communication and support styles between couples may be of particular benefit in reducing diabetes distress. With greater recognition of common 'content' of unhelpful dialogues (i.e. conflicting or provoking beliefs) which occur between couples living with Type 2 diabetes and which engender distress, there is potential to access and target these more directly via formal intervention. Certainly previous work shows that including partners or family members in interventions designed to improve health-related outcomes in chronic illness is feasible and can be hugely effective-often more so than the equivalent patient-only intervention [27]. Studies have shown that illness beliefs [28,29,30] and communication issues $[31,32]$ in couples living with a chronic condition are amenable to intervention. Given this, future research should focus on the development of a couples or family-based intervention which facilitates the exploration of challenging thoughts about diabetes and addresses conflicting perceptions between family members, which hamper positive communication. Moreover such an intervention should be proactive in equipping families with more effective ideas for coping with emotional and interpersonal conflicts and endorsing collaborative problem-solving. The value of this approach is demonstrated by a telephone- 
based couples intervention which lead to long-term reductions in $\mathrm{HbA1c}$, BMI, and diabetes distress [33].

\subsection{Shortcomings}

On average, participating couples had low levels of diabetes distress, and participants with Type 2 diabetes had relatively well controlled HbA1c, with a low incidence of diabetesrelated complications. It is therefore difficult to generalise the findings beyond a wellcontrolled population of people with Type 2 diabetes. Recruiting participants from a secondary care setting may provide greater scope for investigation as experiences of diabetes distress are likely to be substantially greater [34]. The poor response rate at baseline ( $8 \%)$ also invites a significant degree of non-response bias. Participants who agreed to take part in the survey may be distinct from individuals with diabetes who did not respond, possibly across important sociodemographic or medical parameters; which may diminish the representativeness of the current sample.

In addition, we monitored change in various medical parameters such as the onset of diabetes-related complications, $\mathrm{HbAlc}$, diabetes treatment, and the change in health status for partners - the latter had an important influence on experience of distress overtime. Many of these medical parameters however did not feature in the final regression models, suggesting they had minimal influence on variation of distress in the sample as a whole. Despite this, important factors such as change in financial/ occupational circumstances or treatment plan (e.g. attendance at an education programme or change to polypharmacy) were not accounted for in this study. In light of previous research [35-37] these variables may have influenced distress scores beyond that of the IPQ-R, so findings should be interpreted with caution.

\subsection{Conclusion}

This study provides novel and useful information to better understand the interpersonal constructs of diabetes distress. In day to day life, incongruities about diabetes may signify problems with how couples communicate about Type 2 diabetes, which in turn may influence how they support one another. This work identifies that negative beliefs about Type 2 diabetes and incongruity between couples beliefs may continue to impact emotional wellbeing unless actively targeted through a suitable psychosocial intervention. 


\section{Acknowledgements:}

The authors would like to thank the General Practices in Northern Ireland who facilitated recruitment for this study and the individuals with Type 2 diabetes and their partners/ family who participated.

\section{Funding:}

This study was funded by the Department of Education and Learning at Queen's University Belfast.

\section{References}

[1] Berry E, Davies M, Dempster M. Illness perception clusters and relationship quality are associated with diabetes distress in adults with Type 2 diabetes. Psychol Health Med 2017a;8506:1-9. doi:10.1080/13548506.2017.1281976.

[2] Dempster M, Mccarthy T, Davies M. Psychological adjustment to Type2 diabetes and relationship quality. Diabet Med 2011;28:487-92. doi:10.1111/j.1464-5491.2010.03214.x.

[3] White P, Smith SM, Hevey D, O'Dowd T. Understanding type 2 diabetes: Including the family member's perspective. Diabetes Educ 2009;35:810-7. doi:10.1177/0145721709340930.

[4] Wu LM, Mohamed NE, Winkel G, Diefenbach M a. Patient and spouse illness beliefs and quality of life in prostate cancer patients. Psychol Heal 2013;28:355-68.

doi:10.1080/08870446.2012.722219.

[5] Dempster M, McCorry NK, Brennan E, Donnelly M, Murray LJ, Johnston BT. Illness perceptions among carer-survivor dyads are related to psychological distress among Oesophageal cancer survivors. J Psychosom Res 2011;70:432-9. doi:10.1016/j.jpsychores.2010.07.007.

[6] Searle A, Norman P, Thompson R, Vedhara K. Illness representations among patients with type 2 diabetes and their partners: Relationships with self-management behaviors. $\mathrm{J}$ Psychosom Res 2007;63:175-84. doi:10.1016/j.jpsychores.2007.02.006. 
[7] Pereira MG, Pedras S, Machado JC, Ferreira G. Partners' representations of diabetes as mediators between patients' representations and adherence to self-care behaviors, in type 2 diabetes. Psychol Heal Med 2016;21:707-14. doi:10.1080/13548506.2015.1118517.

[8] Dimitraki G, Karademas EC. The association of type 2 diabetes patient and spouse illness representations with their well-being: A dyadic approach. Int J Behav Med 2014;21:230-9. doi:10.1007/s 12529-013-9296-z.

[9] Fisher L, Skaff MM, Mullan JT, Arean P, Glasgow R, Masharani U. A longitudinal study of affective and anxiety disorders, depressive affect and diabetes distress in adults with type 2 diabetes. Diabet Med 2008;25:1096-101. doi:10.1111/j.1464-5491.2008.02533.x.

[10] Fisher L, Mullan JT, Arean P, Glasgow RE, Hessler D, Masharani U. Diabetes distress but not clinical depression or depressive symptoms is associated with glycemic control in both cross-sectional and longitudinal analyses. Diabetes Care 2010;33:23-8. doi:10.2337/dc09-1238.

[11] Sasi Sekhar TVD, Kodali M, Burra KC, Muppala BS, Gutta P, Bethanbhatla MK. Self care activities, diabetic distress and other factors which affected the Glycaemic control in a tertiary care teaching hospital in South India. J Clin Diagnostic Res 2013;7:857-60. doi:10.7860/JCDR/2013/5726.2958.

[12] Skinner TC, Carey ME, Cradock S, Dallosso HM, Dalyb H, Davies MJ, et al. Comparison of illness representations dimensions and illness representation clusters in predicting outcomes in the first year following diagnosis of type 2 diabetes: Results from the DESMOND trial. Psychol Heal 2011;26:321-35. doi:10.1080/08870440903411039.

[13] Polonsky WH, Fisher L, Earles J, Dudl RJ, Lees J, Mullan J, et al. Assessing psychosocial distress in diabetes: Development of the Diabetes Distress Scale. Diabetes Care 2005;28:626-31. doi:10.2337/diacare.28.3.626.

[14] Fisher L, Hessler DM, Polonsky WH, Mullan J. When is diabetes distress clinically meaningful? Establishing cut points for the diabetes distress scale. Diabetes Care 2012;35:259-64. doi:10.2337/dc11-1572.

[15] Cronbach LJ. Coefficient alpha and the internal structure of tests. Psychometrika 1951;16:297-334. doi:10.1007/BF02310555. 
[16] Beck AT, Steer RA, Carbin MG. Psychometric properties of the Beck Depression Inventory: Twenty-five years of evaluation. Clin Psychol Rev 1988;8:77-100. doi:10.1016/0272-7358(88)90050-5.

[17] Polonsky WH, Fisher L, Hessler D, Johnson N. Emotional Distress in the Partners of Type 1 Diabetes Adults: Worries About Hypoglycemia and Other Key Concerns. Diabetes Technol Ther 2016;18:292-7. doi:10.1089/dia.2015.0451.

[18] Moss-Morris R, Weinman J, Petrie K, Horne R, Cameron L, Buick D. The revised Illness Perception Questionnaire (IPQ-R). Psychol Heal 2002;17:1-16. doi:10.1080/08870440290001494.

[19] Weinman J, Petrie KJ, Sharpe N, Walker S. Causal attributions in patients and spouses following a heart attack and subsequent lifestyle changes. Br J Health Psychol 2000:263-73. [20] Allison PD. Change Scores as Dependent Variables in Regression Analysis. Sociol Methodol 1990;20:93-114. doi:10.2307/271083.

[21] National Institute for Health and Care Excellence. Clinical Guideline NG28. Type 2 diabetes in adults: management. Natl Inst Heal Care Excell 2018:1-57. http://www.nice.org.uk/guidance/ng28; 2015 [accessed 8 February 2018]

[22] Cohen J. Statistical power analysis for the behavioral sciences. 2nd ed. Hillsdale, NJ: Lawrence Erlbaum Associates; 1988.

[23] Hessler DM, Fisher L, Mullan JT, Glasgow RE, Masharani U. Patient age: A neglected factor when considering disease management in adults with type 2 diabetes. Patient Educ Couns 2011;85:154-9. doi:10.1016/j.pec.2010.10.030.

[24] Meltzer D, Egleston B. How patients with diabetes perceive their risk for major complications. Eff Clin Pract 2000;3:7-15.

[25] Martinez K, Lockhart S, Davies M, Lindsay JR, Dempster M. Diabetes distress, illness perceptions and glycaemic control in adults with type 2 diabetes. Psychol Health Med 2017;23:1-7. doi:10.1080/13548506.2017.1339892.

[26] Gonzalez JS, Shreck E, Psaros C, Safren SA. Distress and type 2 diabetes-treatment adherence: A mediating role for perceived control. Heal Psychol 2014;34:505-13. doi:10.1037/hea0000131 
[27] Berry E, Davies M, Dempster M. Exploring the effectiveness of couples interventions for adults living with a chronic physical illness: A systematic review. Patient Educ Couns 2017b;100:1287-303. doi:10.1016/j.pec.2017.02.015.

[28] Ågren S, Evangelista LS, Hjelm C, Strömberg A. Dyads affected by chronic heart failure: A randomized study evaluating effects of education and psychosocial support to patients with heart failure and their partners. J Card Fail 2012;18:359-66. doi:10.1016/j.cardfail.2012.01.014.

[29] Northouse LL, Mood DW, Schafenacker A, Montie JE, Sandler HM, Forman JD, et al. Randomized clinical trial of a family intervention for prostate cancer patients and their spouses. Cancer 2007;110:2809-18. doi:10.1002/cncr.23114.

[30] Mishel MH, Belyea M, Germino BB, Stewart JL, Bailey DE, Robertson C, et al. Helping patients with localized prostate carcinoma manage uncertainty and treatment side effects: Nurse-delivered psychoeducational intervention over the telephone. Cancer 2002;94:185466. doi:10.1002/cncr.10390.

[31] Heinrichs N, Zimmermann T, Huber B, Herschbach P, Russell DW, Baucom DH. Cancer distress reduction with a couple-based skills training: A randomized controlled trial. Ann Behav Med 2012;43:239-52. doi:10.1007/s12160-011-9314-9.

[32] Kuijer R, Buunk B, De Jong G, Ybema J, Sanderman R. Effects of a brief intervention program for patients with cancer and their partners on feelings of inequity, relationship quality and psychological distress. Psychooncology 2004;13:321-34. doi:10.1002/pon.749.

[33] Trief PM, Fisher L, Sandberg J, Cibula DA, Dimmock J, Hessler DM, et al. Health and psychosocial outcomes of a telephonic couples behavior change intervention in patients with poorly controlled type 2 diabetes: A randomized clinical trial. Diabetes Care 2016;39:216573. doi:10.2337/dc16-0035.

[34] Stoop CH, Nefs G, Pop VJ, Wijnands-van Gent CJM, Tack CJ, Geelhoed-Duijvestijn PHLM, et al. Diabetes-specific emotional distress in people with Type 2 diabetes: A comparison between primary and secondary care. Diabet Med 2014;31:1252-9. doi:10.1111/dme.12472. 
[35] Ervasti J, Kivimäki M, Dray-Spira R, Head J, Goldberg M, Pentti J, et al. Psychosocial factors associated with work disability in men and women with diabetes: A pooled analysis of three occupational cohort studies. Diabet Med 2016;33:208-17. doi:10.1111/dme.12821.

[36] Cleal B, Panton UH, Willaing I, Holt RIG. Diabetes and depression in Denmark 19962010: national data stratified by occupational status and annual income. Diabet Med 2017;34:108-14. doi:10.1111/dme.13187.

[37] Polonsky WH, Henry RR. Poor medication adherence in type 2 diabetes: Recognizing the scope of the problem and its key contributors. Patient Prefer Adherence 2016;10:1299306. doi:10.2147/PPA.S106821. 
Table 1: Baseline participant demographic \& clinical parameters

Persons with Type 2 Partners $(N=75)$

Diabetes $(N=75)$

Gender $(n)(\%)$

- Male

- Female

Age (av. / std.)

Ethnicity $(n)(\%)$

- Caucasian

- Asian/Asian British

- Black/African/Caribbean/Black British

Children living at home $(n)(\%)$

- No

- Yes

Relationship type (n) (\%)

- Partner/ spouse

- Relative/ family member

Duration of diabetes (av. / std.)

Medication for diabetes $(n)(\%)$

- No

- Yes

Insulin use $(n)(\%)$

- No

- Yes

Diabetes-related complications $(n)(\%)$

- No

- Yes

Partner diabetes $(n)(\%)$

- No

- Yes

Partner other chronic illness $(n)(\%)$

- No

- Yes

HbAlc (mmol/mol (av. (std.))
$51(68 \%)$

$24(32 \%)$

$67.97(10.60)$

$22(29.3 \%)$

$53(70.7)$

$65.85(11.41)$

$72(96 \%)$

$1(1.2 \%)$

$2(2.7 \%)$

$62(82.7 \%)$

$13(17.3 \%)$

$72(96 \%)$

$3(4 \%)$

$9.93(8.73)$

$6(8 \%)$

$67(89.3 \%)$

$64(85.3 \%)$

$11(14.7 \%)$

$68(90.7 \%)$

$6(8 \%)$

74 (98.7\%)

$1(1.3 \%)$

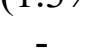


Table 2: Regression model summary at baseline ${ }^{1}$ and 12 month follow-up ${ }^{2}$ for each diabetes distress subscale

\begin{tabular}{|c|c|c|c|c|c|c|c|c|c|c|c|c|c|c|c|c|}
\hline & \multicolumn{2}{|c|}{$\begin{array}{l}\text { Regimen-related } \\
\text { distress }^{1}\end{array}$} & \multicolumn{2}{|c|}{$\begin{array}{l}\text { Regimen-related } \\
\text { distress }^{2}\end{array}$} & \multicolumn{2}{|c|}{$\begin{array}{l}\text { Emotional } \\
\text { burden }^{1}\end{array}$} & \multicolumn{2}{|c|}{$\begin{array}{l}\text { Emotional } \\
\text { burden }^{2}\end{array}$} & \multicolumn{2}{|c|}{$\begin{array}{l}\text { Interpersonal } \\
\text { distress }^{1}\end{array}$} & \multicolumn{2}{|c|}{$\begin{array}{l}\text { Interpersonal } \\
\text { distress }^{2}\end{array}$} & \multicolumn{2}{|c|}{$\begin{array}{l}\text { Physician- } \\
\text { related distress }\end{array}$} & \multicolumn{2}{|c|}{$\begin{array}{l}\text { Physician- } \\
\text { related distress }\end{array}$} \\
\hline & Beta & $p$ & Beta & $p$ & Beta & $p$ & Beta & $p$ & Beta & $p$ & Beta & $p$ & Beta & $p$ & Beta & $p$ \\
\hline Gender (pwt2d) & - & - & - & - & - & - & - & - & - & - & - & - & - & - & -.173 & .093 \\
\hline Age (pwt2d) & -.228 & $.041 *$ & -.230 & $.039 *$ & -.318 & $.002 *$ & - & - & -.327 & $.004 *$ & - & - & - & - & - & - \\
\hline Children living at home & - & - & - & - & - & - & - & - & - & - & - & - & - & - & -.347 & $.002 *$ \\
\hline Insulin & - & - & - & - & .246 & $.018 *$ & - & - & .335 & $.002 *$ & - & - & -.115 & .244 & - & - \\
\hline Duration of diabetes & .203 & .067 & & & .315 & $.003 *$ & - & - & - & - & - & - & - & - & - & - \\
\hline Identity (pwt2d) & - & - & .525 & $<.001 *$ & .358 & $.001 *$ & - & - & - & - & - & - & - & - & .437 & $<.001 *$ \\
\hline Timeline A/C (pwt2d) & - & - & - & - & - & - & - & - & - & - & - & - & -.267 & $.009 *$ & - & - \\
\hline Timeline $\mathrm{A} / \mathrm{C}$ (partner) & - & - & - & - & - & - & - & - & - & - & - & - & .287 & $.004 *$ & - & - \\
\hline Consequences (pwt2d) & .337 & $.014 *$ & - & - & .244 & $.018 *$ & .344 & $.002 *$ & .312 & $.004 *$ & .288 & $.026 *$ & - & - & .300 & $.005 *$ \\
\hline Consequences (partner) & -.139 & .216 & - & - & - & - & - & - & - & - & - & - & - & - & & \\
\hline Personal control (pwt2d) & - & - & - & - & -.246 & $.012 *$ & -.121 & .329 & - & - & - & - & - & - & -.414 & $.001 *$ \\
\hline Coherence (partner) & - & - & - & - & - & - & - & - & .305 & $.007 *$ & - & - & - & - & - & - \\
\hline Timeline cyclical (pwt2d) & - & - & - & - & - & - & - & - & - & - & - & - & .306 & $.004 *$ & - & - \\
\hline Timeline cyclical (partner) & - & - & - & - & .185 & .074 & - & - & - & - & - & - & - & - & - & - \\
\hline Timeline A/C X & - & - & - & - & - & - & -.342 & $.004 *$ & -.223 & $.027 *$ & -.692 & $<.001 *$ & -.473 & $<.001 *$ & - & - \\
\hline Consequences X & .360 & $.003 *$ & - & - & .167 & .107 & - & - & - & - & -.134 & .275 & - & - & - & - \\
\hline Personal control X & .423 & $<.001 *$ & .257 & $.041 *$ & - & - & - & - & - & - & - & - & - & - & - & - \\
\hline Treatment control X & - & - & - & - & - & - & - & - & - & - & - & - & -.107 & .288 & - & - \\
\hline Timeline cyclical X & -.207 & .061 & - & - & .213 & $.044 *$ & .435 & $<.001 *$ & -.133 & .215 & .204 & .089 & - & - & .433 & $<.001 *$ \\
\hline Coherence X & - & - & .309 & $.005 *$ & - & - & - & - & - & - & - & - & - & - & - & - \\
\hline
\end{tabular}

Note. pwt $2 \mathrm{~d}=$ person with Type 2 diabetes; Timeline $\mathrm{A} / \mathrm{C}=$ Timeline acute/chronic; $\mathrm{X}=$ interaction terms; $\beta e t a=$ standardised coefficients; $* p<0.05($ in $\mathbf{b o l d})$

${ }^{2}$ Regimen-related distress $=$ adjusted $R^{2}=0.552 ; \mathrm{F}(5,40)=13.916 ; p<.001$

${ }^{2}$ Emotional burden $=$ adjusted $R^{2}=0.553 ; F(5,40)=11.392 ; p<.001$

${ }^{2}$ Interpersonal distress $=$ adjusted $R^{2}=0.494 ; F(6,39)=7.675 ; p<.001$

${ }^{2}$ Physician-related distress $=$ adjusted $R^{2}=0.624 ; F(6,39)=12.604 ; p<.001$ 


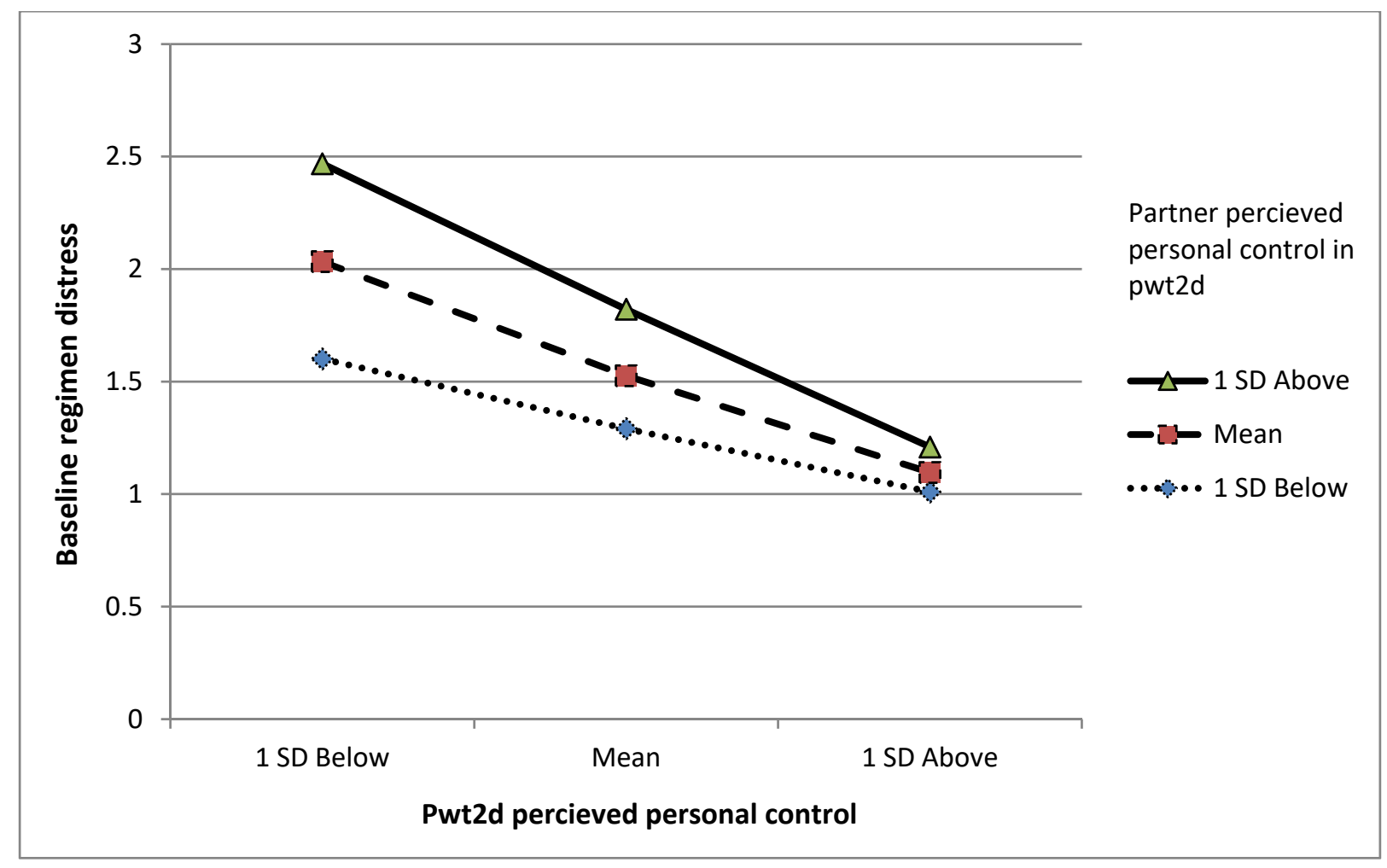

Figure 1. Simple slopes analysis for the interaction between pwt2d perceptions of personal control and partners' perceptions of personal control at baseline

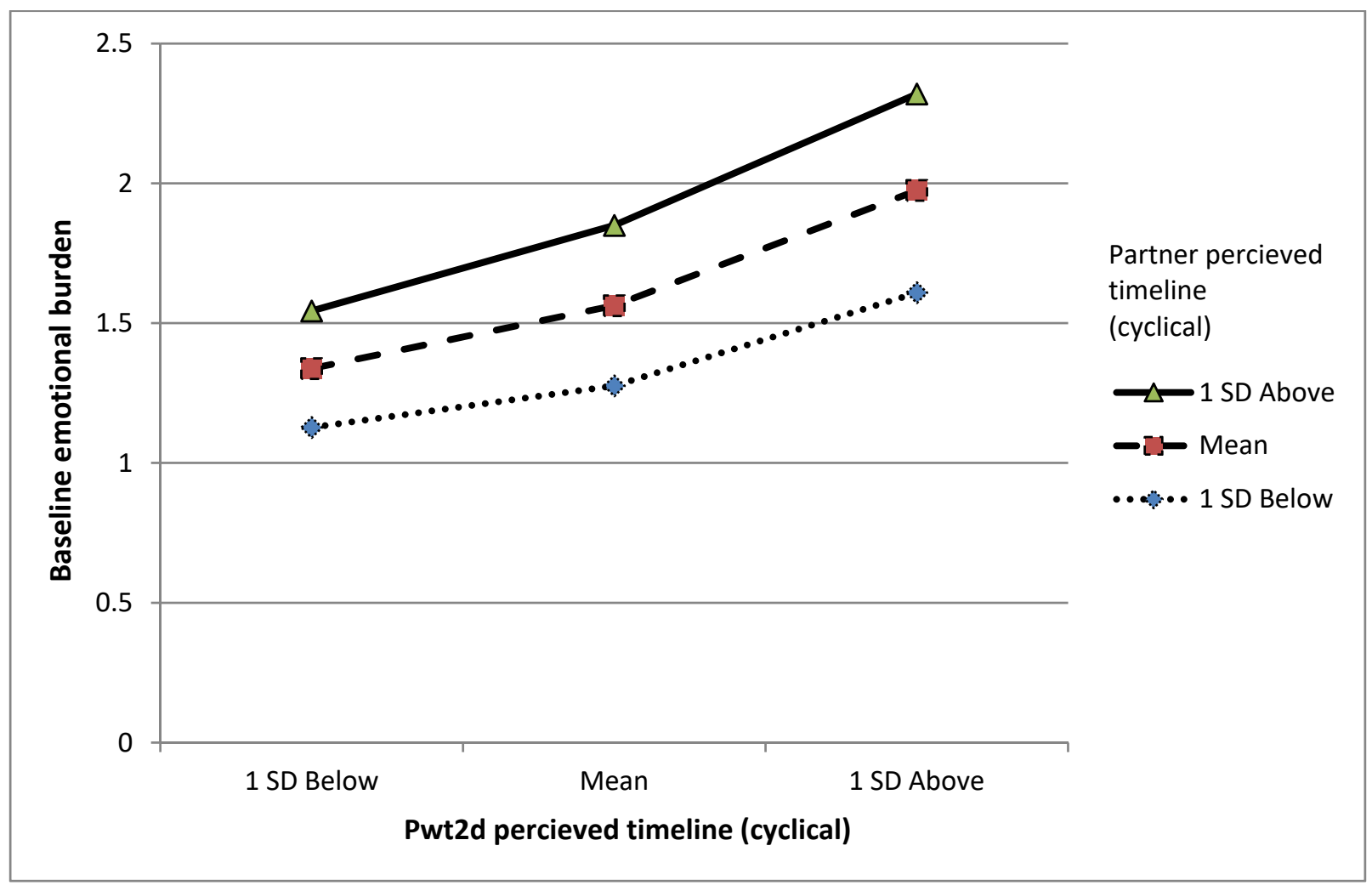

Figure 2. Simple slopes analysis for the interaction between pwt $2 \mathrm{~d}$ and partners' perception of the frequency of diabetes-related symptoms at baseline 


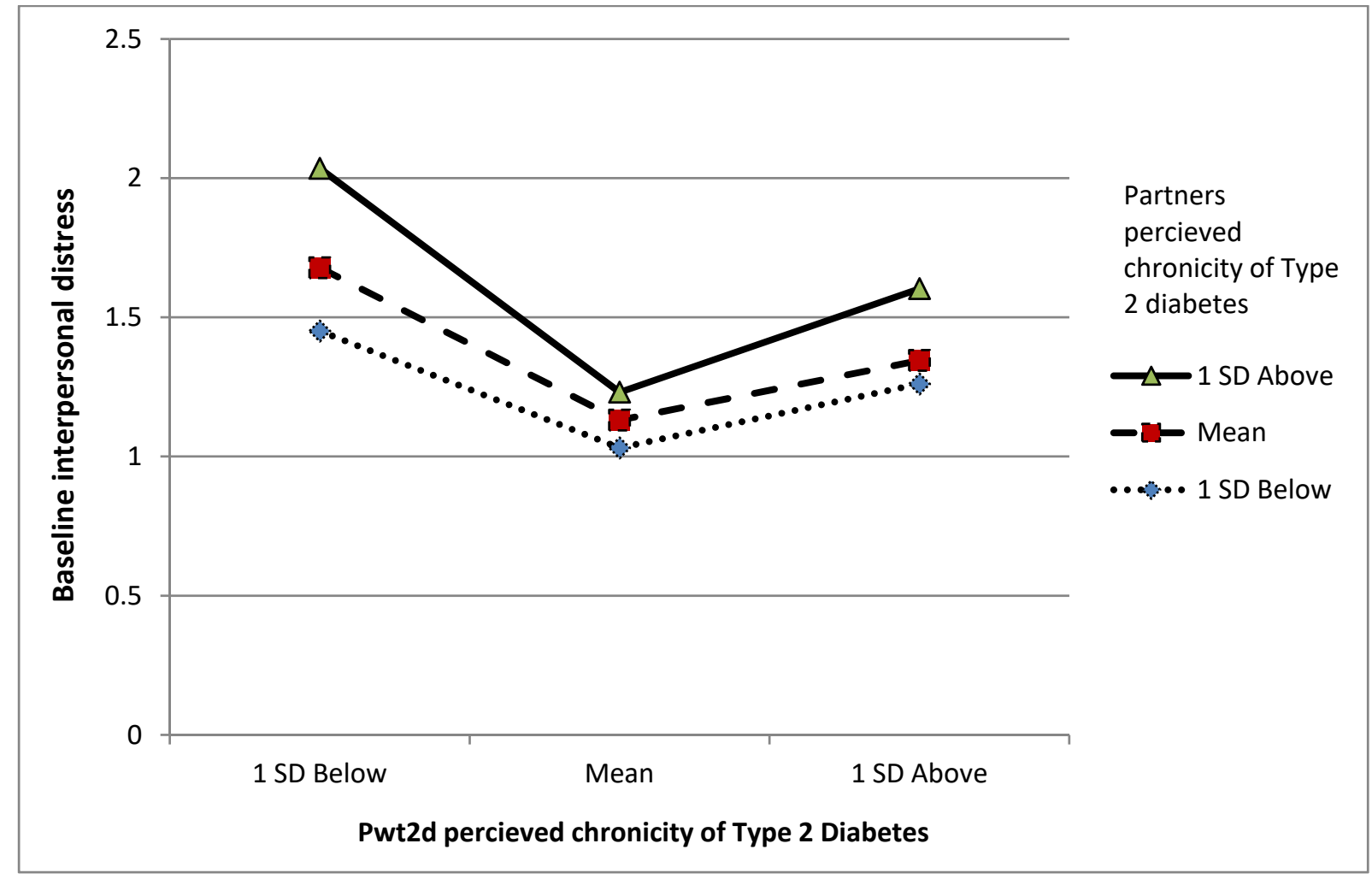

Figure 3. Simple slopes analysis for the interaction between pwt2d and partners' perceptions of the chronicity of Type 2 diabetes at baseline 
Appendix A: Simple slopes graphs for each interaction at 12 months follow-up

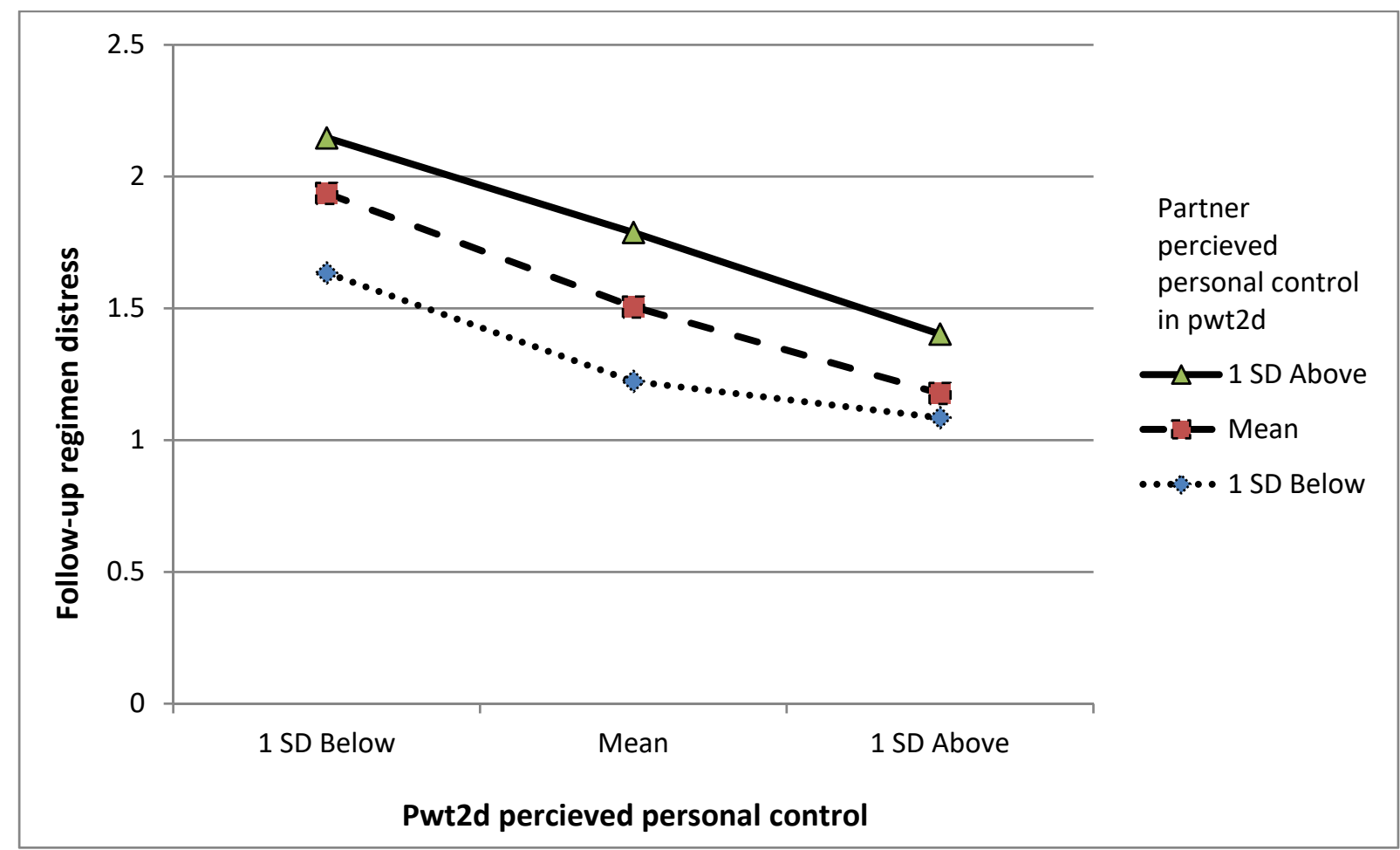

Figure A1. Simple slopes analysis for the interaction between pwt2d perceptions of personal control and partners' perceptions of personal control at 12 month follow-up

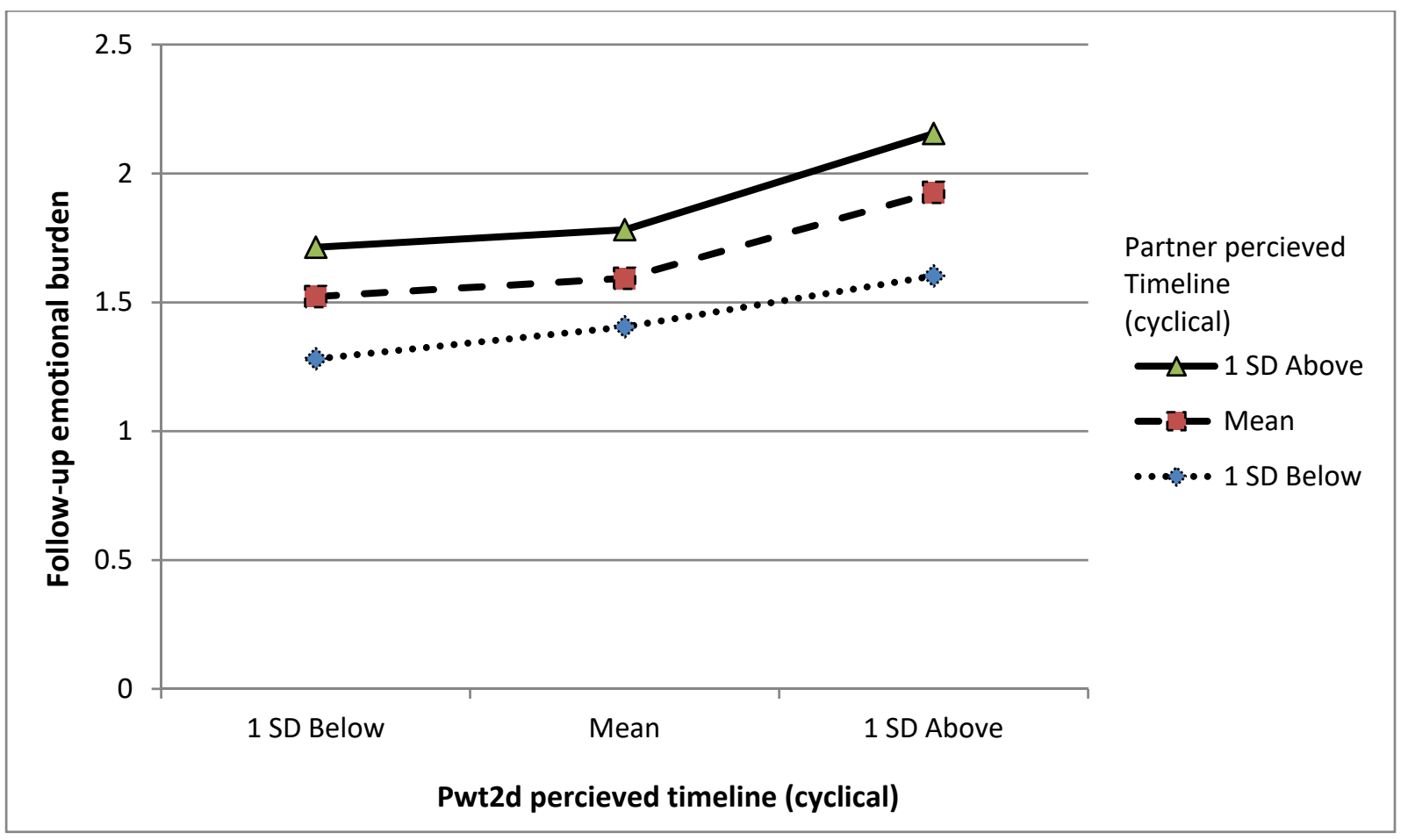

Figure A2. Simple slopes analysis for the interaction between pwt2d and partners' perception of the frequency of diabetes-related symptoms at 12 month follow-up 


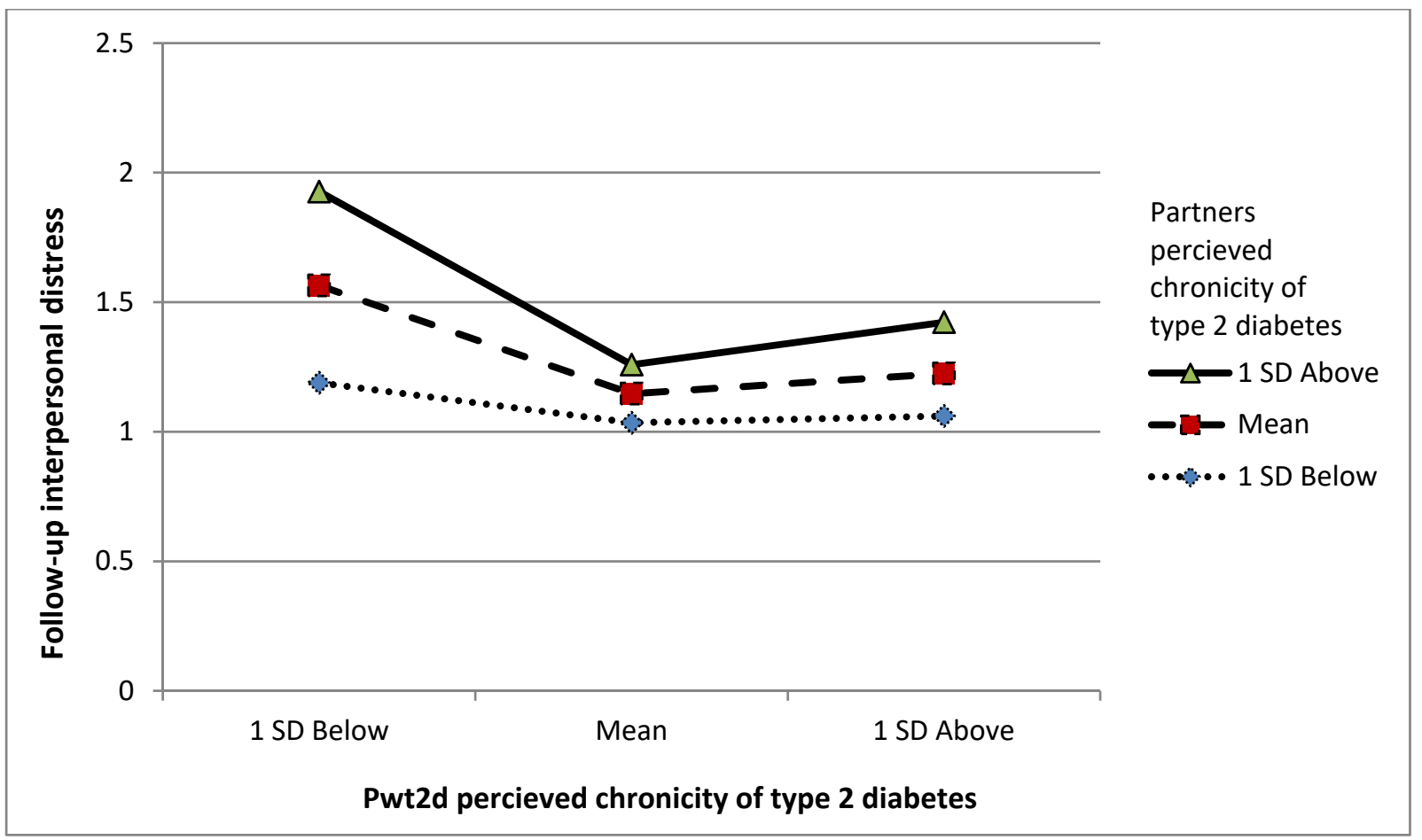

Figure A3. Simple slopes analysis for the interaction between pwt2d and partners' perceptions of the chronicity of Type 2 diabetes at 12 month follow-up 
Appendix B: Scores across outcome measures at baseline and 12 month follow-up

Table A1: Means and standard deviations across diabetes distress and illness perception subscales at baseline and 12 month follow-up for persons with Type 2 diabetes.

\begin{tabular}{|c|c|c|}
\hline & Baseline & 12 months \\
\hline \multicolumn{3}{|l|}{ Diabetes Distress Scale (av. / std.) } \\
\hline - Physician-related distress & $1.09(0.24)$ & $1.20(0.52)$ \\
\hline - Emotional burden & $1.57(0.67)$ & $1.56(0.79)$ \\
\hline - $\quad$ Regimen-related distress & $1.56(0.68)$ & $1.55(0.70)$ \\
\hline - Interpersonal distress & $1.17(0.37)$ & $1.22(0.46)$ \\
\hline - Total & $1.35(0.35)$ & $1.41(0.52)$ \\
\hline \multicolumn{3}{|c|}{ Revised Illness Perception Questionnaire (av. / std.) } \\
\hline - IPQ-R Identity & $2.09(1.99)$ & $2.44(2.65)$ \\
\hline - IPQ-R Timeline acute/ chronic & $18.37(1.38)$ & $17.95(2.51)$ \\
\hline - IPQ-R Consequences & $16.86(2.85)$ & $16.74(3.49)$ \\
\hline - IPQ-R Personal control & $20.23(2.18)$ & $19.98(1.49)$ \\
\hline - IPQ-R Treatment control & $14.21(1.81)$ & $13.81(2.22)$ \\
\hline - IPQ-R Illness coherence & $12.74(3.16)$ & $12.67(3.60)$ \\
\hline - IPQ-R Timeline cyclical & $9.47(3.61)$ & $8.74(3.09)$ \\
\hline - IPQ-R Emotional representations & $13.00(3.52)$ & $13.05(3.94)$ \\
\hline - IPQ-R Emotional cause & $12.05(3.91)$ & $12.14(4.05)$ \\
\hline - IPQ-R Behavioural cause & $11.05(3.79)$ & $11.79(3.50)$ \\
\hline - IPQ-R Externalised cause & $17.00(3.34)$ & $17.04(3.17)$ \\
\hline
\end{tabular}

Note. av. $=$ average, std.$=$ standard deviation, IPQ-R $=$ Revised Illness Perception Questionnaire 
Table A2: Means and standard deviations across diabetes distress and illness perception subscales at baseline and 12 month follow-up for partners.

\begin{tabular}{|c|c|c|}
\hline & Baseline & 12 months \\
\hline \multicolumn{3}{|l|}{ Diabetes Distress Scale (av. / std.) } \\
\hline - Physician-related distress & $1.15(0.34)$ & $1.45(0.98)$ \\
\hline - Emotional burden & $1.51(0.64)$ & $1.66(1.04)$ \\
\hline - Regimen-related distress & $1.55(0.64)$ & $1.64(0.90)$ \\
\hline - Interpersonal distress & $1.31(0.59)$ & $1.47(0.95)$ \\
\hline - Total & $1.40(0.44)$ & $1.57(0.87)$ \\
\hline \multicolumn{3}{|c|}{ Revised Illness Perception Questionnaire (av. / std.) } \\
\hline - IPQ-R Identity & $2.35(2.28)$ & $2.16(2.53)$ \\
\hline - IPQ-R Timeline acute/ chronic & $18.77(2.85)$ & $17.53(3.10)$ \\
\hline - IPQ-R Consequences & $17.44(4.58)$ & $17.65(4.10)$ \\
\hline - IPQ-R Personal control & $20.19(2.80)$ & $20.00(2.99)$ \\
\hline - IPQ-R Treatment control & $14.30(1.88)$ & $13.74(2.36)$ \\
\hline - IPQ-R Illness coherence & $12.14(4.26)$ & $12.30(3.39)$ \\
\hline - IPQ-R Timeline cyclical & $9.33(4.88)$ & $8.10(3.22)$ \\
\hline - IPQ-R Emotional representations & $14.02(3.77)$ & $13.65(4.10)$ \\
\hline - IPQ-R Emotional cause & $11.81(4.05)$ & $12.01(4.75)$ \\
\hline - IPQ-R Behavioural cause & $10.05(3.06)$ & $10.35(3.43)$ \\
\hline - IPQ-R Externalised cause & $17.30(3.33)$ & $17.01(3.14)$ \\
\hline
\end{tabular}

Note. av. $=$ average, std. $=$ standard deviation, IPQ-R $=$ Revised Illness Perception Questionnaire 